I arrived this year with my family my wife, 8-year-old son and 14-year-old daughter. Within just 30 minutes of our arrival our kids came back with cups full of free candy floss, boxes of chocolates and sweets galore! Most stands seemed to be giving out mints and sweets to entice our attention to buy their products. Please tell me I am getting cynical in my old age (I'm 47) but really, really, should we be endorsing such an image at a dental event such as this? This is a dental event aimed at preventing dental disease ... or have I got it so wrong in the past and should I be giving candy floss out to my patients to promote my practice and ensure that my books are full over this coming recession? Surely with a little imagination and effort stands should promote healthy foods. I look forward next year to more sweets and more fillings!

S. Michaels

Bovingdon

DOI: 10.1038/sj.bdj.2012.7

\section{FURTHER NHS AMAZEMENT}

Sir, I write in response to the letter by H. R. Read (BDJ 2011; 211: 399) which certainly made me chuckle at a time when I too am frustrated with the state of our NHS.

I graduated in 2007 and after completing my vocational training, decided to go down the secondary care route, working as a senior house officer for three years. The experience was invaluable.

Four months ago, I decided I wanted to tread back into practice: the start of which I didn't expect to be a very stressful few months.

I thought I'd begin with a locum whilst looking for a permanent associate position that took my fancy. Having registered with about five different locum agencies, I was notified I couldn't work immediately without a performer number and having been out of primary care for the last three years, my previous PCT assured me my performer number was no longer active. They went on to tell me that without a job, I couldn't apply for a performer number. So - no performer number, no job. And no job, no performer number. Delightful.

Fortunately, I found a practice that was willing to employ me two and a half months down the line, thus giving me time to apply for a number. What I did not realise was that two and a half months was insufficient time for the primary care agency to hand me the six digits I needed. Their reasoning was that I hadn't worked in primary care for the last three years and thus, I'd need another CRB check (bear in mind my last one had been no longer than two months previous to that), a couple of references and a Regulations Specialist (whoever that is) would have to review my application. It would then be sent to a performer review group and subsequently, the dental advisor of the region would likely call me in for an interview! All of this for what? For wanting to gain as much experience as I could following graduation so that when I went into practice, I would know how to do things properly and be able to deal with complex cases without having to refer them on? Don't get me wrong. I understand there are vast differences in primary and secondary care which will take time to adapt to but I don't think this problem will be solved by those means!

I was finally included on a list. But alas, three weeks after my initial proposed work start date. This did not come without consequences. Every practice has targets and mine was no exception. Twelve days of patient cancellations is no joke when you already have a UDA shortfall and although they realised the delay was no fault of my own, the contract that had been signed was no longer valid and some of my working days got lost to a dentist who was able to start immediately.

When the new contract was initiated, the DH wanted to improve access. I was volunteering my skills as a dentist and was being told that I was not allowed to work because I didn't have the six digits of a performer number. Is this not a threat to my livelihood? The fact that I have a BDS degree, an MJDF qualification and am well over my necessary CPD hours did not matter.

Surely the number you are given during your VT year (or equivalent) should be yours to keep throughout your career? Admittedly, I'll be glad to see the coming dissolution of the primary care trusts. Maybe at some point, we can pursue our career goals without having to worry about being jobless as a result of ever increasing bureaucracy.

\section{S. Kaka}

Studham

DOI: 10.1038/sj.bdj.2012.8

\section{NOT SO HARD TO SWALLOW}

Sir, an advertisement in a recent edition (BDJ 211[9]) showed two examples of small unilateral removable partial dentures. There have been case reports of such small dentures being swallowed or inhaled..$^{1,2}$

If there is an adverse incident, practitioners must justify their treatment planning and decisions regarding the way that treatment is provided.

It is our opinion that the decision to provide a small unilateral partial denture in acrylic resin or any other plastic material would be difficult if not impossible to defend, whether before the General Dental Council or in a court of law.

M. Gregory, R. Jagger

Bristol

1. Hashmi S, Walter J, Smith W, Latis S. Swallowed partial dentures. JR Soc Med 2004; 97: 72-75.

2. Knowles J E. Inhalation of dental plates - a hazard of radiolucent materials. J Laryngol Otol 1991; 105: 681-682.

\section{Managing Director Susan Drake} responds on behalf of Sun Dental Laboratories (UK) Ltd: Our technicians are regularly questioned by dentists about the possibility of that problem arising and how this could be alleviated.

The reply from them is quite simple: it is up to the prescribing dentist to prescribe appropriate treatment for each patient; as a dental laboratory we have absolutely no influence on the prescriber's decision and as such only facilitate their prescriptions.

As we are not legal professionals we cannot comment on whether the dentist's decision would be difficult or impossible to defend at the GDC or a court of law.

The advertisement was merely a product offer as a 'temporary' replacement for patients unable to afford an implant and has now been withdrawn from further publication to avoid any confusion. DOI: 10.1038/sj.bdj.2012.9 